\title{
Human-wildlife conflict in Mozambique: a national perspective, with emphasis on wildlife attacks on humans
}

\author{
Kevin M. Dunham, Andrea Ghiurghi, Rezia Cumbi and Ferdinando Urbano
}

\begin{abstract}
Human-wildlife conflicts are common across Africa. In Mozambique, official records show that wildlife killed 265 people during 27 months (July 2006 to September 2008). Crocodile Crocodylus niloticus, lion Panthera leo, elephant Loxodonta africana and hippopotamus Hippopotamus amphibius caused most deaths but crocodiles were responsible for $66 \%$. Crocodile attacks occurred across Mozambique but $53 \%$ of deaths occurred in districts bordering Lake Cabora Bassa and the Zambezi River. Hippopotamus attacks were also concentrated here. Lion attacks occurred mainly in northern Mozambique and, while people were attacked by elephants across the country, $67 \%$ of deaths occurred in northern Mozambique. Attacks by lions, elephants or hippopotamuses were relatively rare but additional data will probably show that attacks by these species are more widespread than the preliminary records suggest. Buffalo Syncerus caffer, hyaena Crocuta crocuta and leopard Panthera pardus were minor conflict species. Good land-use planning, a long-term solution to many conflicts, is particularly relevant in Mozambique, where the crocodile and hippopotamus populations of protected areas are often in rivers that border these areas, and cause conflicts outside them, and where people commonly live within protected areas. Poverty may prompt fishermen to risk crocodile attack by entering rivers or lakes. The high incidence of conflicts near Limpopo and South Africa's Kruger National Parks (both within the Great Limpopo Transfrontier Conservation Area) highlights the problems created for people by facilitating the unrestricted movement of wildlife between protected areas across their land.
\end{abstract}

Keywords Animal attacks, crocodile, elephant, hippopotamus, human-wildlife conflict, lion, Mozambique

\section{Introduction}

Tuman-wildlife conflicts are common across Africa 1 (Hoare, 2000; Ogada et al., 2003; Inskip \& Zimmerman,

Kevin M. Dunham (Corresponding author) P.O. Box CH385, Chisipite, Harare, Zimbabwe. E-mail faykevin@zol.co.zw

Andrea Ghiurghi and Ferdinando Urbano agreCo G.E.I.E. c/o Agriconsulting S.p.A., Rome, Italy

Rezia Cumbi Direcção Nacional de Terras e Florestas, Maputo, Mozambique

Received 21 April 2009. Revision requested 29 June 2009.

Accepted 31 July 2009.
2009). Concerns about human-wildlife conflicts that are fatal to people prompted the Mozambican government to collect national statistics about human-wildlife conflict and, here, we analyse the first 2 years of data. We concentrate on examining wildlife attacks on people from a national perspective by comparing the incidence and relative importance of attacks by different wildlife species and by mapping the spatial distribution of attacks across Mozambique. Wildlife attacks on people are rare compared with those on crops or domestic animals. Thus, there have been few national studies of attacks on people by different wildlife species or of the spatial distribution of such attacks. The study of lion Panthera leo attacks on people in Tanzania (Packer et al., 2005) is a notable exception.

Human-wildlife conflict is a complex topic (Hoare, 2001) and this study does not provide new solutions. Rather, we document which wildlife species cause fatal conflicts in Mozambique and where. With this information, more appropriate species-level techniques for conflict mitigation (Hoare, 2001; Chardonnet et al., 2008; Fergusson, 2008) can be applied in the appropriate regions. Most previous studies of human-wildlife conflict in Mozambique are government reports that are not publicly available or reports that are available only in the grey literature (Osborn, 1998; Osborn \& Anstey, 2002; Anderson \& Pariela, 2005; Begg et al., 2007).

\section{Methods}

Mozambique (land area $786,380 \mathrm{~km}^{2}$; Fig. 1) comprises 10 provinces, and for this analysis is divided into 142 districts (128 administrative districts and 14 cities). With each district representing, on average, $<1 \%$ of the area of Mozambique, the mapping of conflicts by district provides a good representation of the spatial distribution of conflicts across Mozambique as a whole. Although districts are political entities, they were used successfully by Packer et al. (2005) to map human-lion conflicts in Tanzania and to determine some of the ecological processes influencing the intensity of lion attacks on people. The Direcção Nacional de Terras e Florestas (DNTF; National Directorate for Land and Forests) of the Ministry of Agriculture in Maputo maintains monthly records of human-wildlife conflicts in Mozambique, as reported by the Serviços Provinciais de Florestas e Fauna Bravia (SPFFB; Provincial Offices of Forest and Wildlife).

After a conflict occurred, details were reported by local people or the local community leader to the head of the 


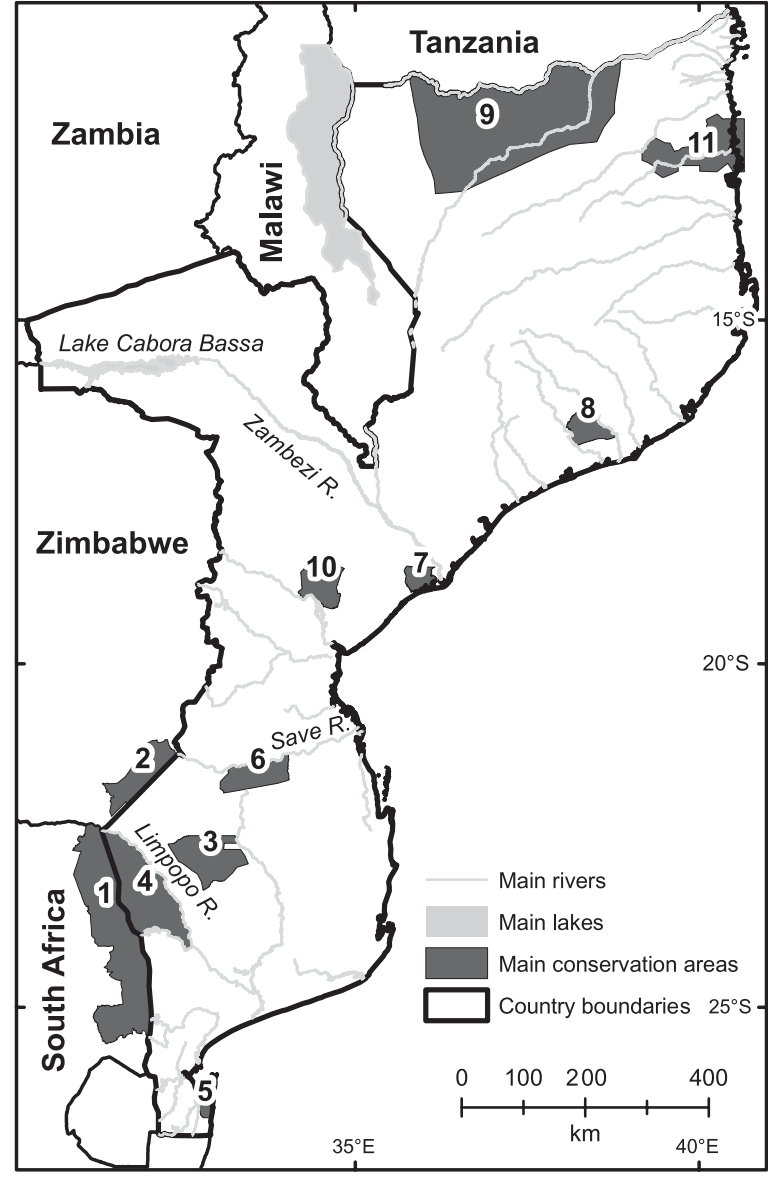

FIG. 1 Mozambique and surrounding countries, showing selected conservation areas and major rivers and lakes. 1, Kruger NP in South Africa; 2, Gonarezhou NP in Zimbabwe; 3, Banhine NP; 4, Limpopo NP; 5, Maputo Elephant Reserve; 6, Zinave NP; 7, Marromeu NR; 8, Gile NR; 9, Niassa NR; 10, Gorongosa NP; 11, Quirimbas NP. NP, National Park; NR, National Reserve.

local administrative post. Data were passed to a wildlife ranger who collated the district records and passed them to Serviços Distritais de Actividades Económicas (SDAE; District Offices of Economic Activities), which were responsible for forwarding the records, by radio or phone, to the SPFFB. These provincial offices sent the records, usually by fax, to the DNTF in Maputo. At each stage (administrative post, SDAE and SPFFB), officials were required to record the information on a standard data sheet that requested the locality and district where the conflict occurred, the date and type of conflict (people killed or injured or crop damage), the name, age and sex of the person affected, their activity when they were attacked and the wildlife species involved, the number of animals killed and the institution responsible for the killing. There was an extra column for other information. Officials were instructed to record any type of injury caused by wildlife. The animals reported killed were killed promptly after officials learnt of the conflict, by specialized official units, authorized members of the private sector (e.g. professional safari hunters) or by local communities. Citizens and officials received no reward or incentive for reporting conflicts, and affected people did not receive compensation. We have not had the opportunity to verify the reports. As far as we are aware there was no political bias in the reporting of conflicts but it is likely that only an extreme bias of this nature would be detected during an analysis of national records. Nonetheless, we are aware that human-wildlife conflict can be a source of political tension in Mozambique (Osborn \& Anstey, 2002).

Each month the wildlife department of the DNTF used the data to prepare a monthly report for the Minister of Agriculture. This analysis is based on these reports, which covered July 2006 to September 2008 inclusive. The reports usually included the numbers of people killed or injured by wildlife, the wildlife species responsible, the month and year when the conflict occurred and the district where it occurred, the number and species of any wild animals killed in response, and sometimes additional details such as the number and species of domestic animals killed or crop damage. The records did not always include the circumstances in which a person was killed or injured. The species featured in the records were mainly large carnivores (particularly crocodile Crocodylus niloticus and lion) and large herbivores (particularly elephant Loxodonta africana and hippopotamus Hippopotamus amphibius), all animals that are both difficult and potentially dangerous for rural people to deal with themselves.

The completeness of the available records is not easily determined. Many records related to the death of or injury to a person or the killing of a large wild animal, perhaps suggesting that conflicts were more likely to be reported to the DNTF if a person was attacked or a large wild animal killed. The records came from 95 districts $(67 \%)$ that together covered $77 \%$ of the area of Mozambique. The absence of a district from the records may indicate a failure to report conflicts in that district or simply the absence of conflicts there. Eight districts that did not feature in the records are both urban areas and provincial capitals, where large animals are likely to be absent or rare. The numbers derived from this analysis may be minimum figures but are unlikely to overestimate the incidence of wildlife attacks on humans.

The term victim is used here to describe a person attacked (i.e. killed or injured) by wildlife. The mortality rate of victims was calculated as the reported number of people killed by a given species of wildlife as a percentage of the total number of people reported killed or injured by the same species. It reflects the probability of a person dying as a consequence of an attack. The calculated rates would overestimate the true rates if minor injuries were under-recorded (although we have no reason to believe that they were). Regardless, interspecies comparisons of rates would be valid.

Crop raiding was reported by district by month/year and by species responsible. Hence, in this analysis, one cropraiding report means that there was a record of the given 
species damaging crops in a stated district during a given month. It was not reported how many fields were raided in that district during that month but sometimes the area of crops damaged was estimated. The term domestic livestock is used here to describe cattle, goats and sheep.

The data set covers only 2 full years and thus is too small to permit an analysis of year-to-year trends. Also, without a long-term data set or comparable data from districts where animals were or were not killed, we could not determine whether killing conflict animals reduced the incidence or severity of conflicts. Statistical tests were conducted using MINITAB v. 14.11 (Minitab Inc., State College, USA).

\section{Results}

During 27 months 265 people were reported killed and 82 injured during conflicts with wildlife. Crocodiles, lions, elephants and hippopotamuses were responsible for most deaths (Table 1), but crocodiles killed more people than all other species combined. Crocodiles killed $66 \%$ of the people for whom the responsible species was reported.

The mortality rate was high for people attacked by elephants $(84 \%)$ or crocodiles $(79 \%)$, and the rate did not differ significantly between the two species (for numbers of people killed or injured by elephants or crocodiles, $\left.\chi_{1}^{2}=0.46, \mathrm{P}=0.5\right)$. For people attacked by lions or hippopotamuses, the mortality rate $(55 \%)$ was significantly less than that for those attacked by elephants or crocodiles (for numbers killed or injured by elephants, crocodiles, lions or hippopotamuses, $\chi_{3}^{2}=16.7, \mathrm{P}=0.001$ ). Only for attacks by buffalo Syncerus caffer could the rate be regarded as relatively low (13\%) but, because the number of people attacked

TABLE 1 The numbers of people reported killed or injured by wildlife in Mozambique and the numbers of individuals of these species reported killed in response to conflicts (source: Direcção Nacional de Terras e Florestas human-wildlife conflict records for July 2006 to September 2008 inclusive).

\begin{tabular}{|c|c|c|c|}
\hline \multirow[b]{2}{*}{ Species } & \multicolumn{2}{|c|}{ No. of people } & \multirow{2}{*}{$\begin{array}{l}\text { No. of } \\
\text { animals killed }\end{array}$} \\
\hline & Killed & Injured & \\
\hline Crocodile Crocodylus niloticus & 134 & 36 & 92 \\
\hline Elephant Loxodonta africana & 31 & 6 & 85 \\
\hline Lion Panthera leo & 24 & 20 & 26 \\
\hline $\begin{array}{l}\text { Hippopotamus } \\
\text { Hippopotamus amphibius }\end{array}$ & 12 & 10 & 60 \\
\hline Buffalo Syncerus caffer & 1 & 7 & 11 \\
\hline Leopard Panthera pardus & 0 & 0 & 1 \\
\hline Snake & 1 & 0 & 0 \\
\hline $\begin{array}{l}\text { Monkey (Cercopithecus } \\
\text { sp. or Papio sp.) }\end{array}$ & 1 & 0 & 0 \\
\hline Jackal (Canis sp.) & 0 & 2 & 2 \\
\hline Dog Canis lupus familiaris & 0 & 1 & 0 \\
\hline Species not stated & 61 & & \\
\hline Total & 265 & 82 & 277 \\
\hline
\end{tabular}

by buffaloes was small, it was not certain that the mortality rate for buffalo attacks was significantly different from the rate for attacks by lions or hippopotamuses (for numbers of people killed or injured by lions, hippopotamuses or buffaloes, $\left.\chi_{2}^{2}=5.045, \mathrm{P}=0.08\right)$.

Lions and crocodiles killed most domestic animals that were reported killed by wildlife, and cattle and goats formed the majority of their domestic animal prey (Table 2). Most reports of crop raiding were of crop damage by elephants or hippopotamuses (Table 3), although it is likely that crop raiding by smaller species, such as bush pig Potamochoerus porcus, baboon Papio spp. and monkey Cercopithecus spp., was usually not recorded. Some records included estimates of the area of crops damaged within a district during the month when damage was reported, and these estimates varied from a median of 3 ha damaged by hippopotamuses ( $\mathrm{n}=24$ records) to a median of 9 ha damaged by elephants ( $\mathrm{n}=62$ records; Mann-Whitney $U=369, \mathrm{P}=0.0003$ ). Sometimes elephants damaged granaries or huts and hippopotamuses attacked boats.

Crocodile, elephant and hippopotamus were the species most frequently killed in response to conflicts (Table 1). Elephants and hippopotamuses were shot more often in relation to the number of their human victims than other species (ratio of the number of animals killed to the number of victims $=2.7: 1$ for hippopotamus, $2.3: 1$ for elephant, 1.4:1 for buffalo, 0.6:1 for lion, and 0.5:1 for crocodile). Although one leopard P. pardus was killed, there was no record of leopards killing or injuring people or killing domestic animals.

Crocodiles attacked people in 46 districts across Mozambique but attacks were concentrated along the Zambezi River: $49 \%$ of attacks and $53 \%$ of deaths occurred in 12 districts that bordered Lake Cabora Bassa or the Zambezi River (Fig. 2a). Attacks on domestic livestock (13 districts; Fig. 2b) were less widespread than those on people and were reported only from central and southern Mozambique. The number of crocodiles killed in a district in response to conflicts (Fig. 2c) was weakly correlated with the number of domestic livestock killed by crocodiles in the same district (Spearman rank correlation $r_{\mathrm{s}}=0.270, \mathrm{P}=0.04, \mathrm{n}=58$

TABLE 2 The numbers of domestic animals reported killed by four wildlife species in Mozambique (source: Direcção Nacional de Terras e Florestas human-wildlife conflict records for July 2006 to September 2008 inclusive).

\begin{tabular}{lccllcr}
\hline Species & Cattle & Goat & Sheep & Chicken & Dog & Total \\
\hline Lion & 117 & 83 & 3 & 4 & 10 & 217 \\
Crocodile & 22 & 38 & 2 & 5 & 0 & 67 \\
Hyaena $^{*}$ & 2 & 12 & 0 & 0 & 0 & 14 \\
Elephant & 3 & 0 & 0 & 0 & 0 & 3 \\
Total & 144 & 133 & 5 & 9 & 10 & 301 \\
\hline
\end{tabular}

${ }^{*}$ Species not stated but probably spotted hyaena Crocuta crocuta 
TABLE 3 The numbers of reports of crop raiding by wildlife species in Mozambique (source: Direcção Nacional de Terras e Florestas human-wildlife conflict records for July 2006 to September 2008 inclusive). Crop raiding was recorded by district by month/year by species responsible. Hence, one report represents a record of the given species damaging crops in a stated district during a given month.

\begin{tabular}{ll}
\hline Species & $\begin{array}{l}\text { No. of district/months when } \\
\text { crop damage reported }\end{array}$ \\
\hline Elephant & 123 \\
Hippopotamus & 56 \\
Buffalo & 3 \\
Pig ${ }^{*}$ Monkey & 3 \\
Not stated & 1 \\
\hline
\end{tabular}

*Probably bush pig Potamochoerus porcus

districts where crocodiles were killed, people attacked or domestic livestock killed by crocodiles) but not with the number of people attacked by crocodiles $\left(r_{\mathrm{s}}=0.073\right.$, $\mathrm{P}=0.6)$.

Hippopotamus attacks on people were less widespread (Fig. 3a) than crop damage (Fig. 3b) and occurred mostly along the Zambezi River: $55 \%$ of attacks and $50 \%$ of deaths occurred in six districts that border Lake Cabora Bassa or the Zambezi River. Hippopotamuses damaged crops mainly in districts along the Zambezi, Save and Limpopo Rivers and in southern Mozambique. The number of hippopotamuses killed in a district (Fig. 3c) was correlated with the number of months when crop raiding by hippopotamuses was reported in that district $\left(r_{\mathrm{s}}=0.432, \mathrm{P}=0.008, \mathrm{n}=36\right.$ districts where hippopotamuses were killed, people attacked or crops raided by hippopotamuses) but not with the number of people in the district who were attacked by hippopotamuses $\left(r_{\mathrm{s}}=-0.018, \mathrm{P}=0.9\right)$.

Lion attacks on people occurred mainly in northern Mozambique (Fig. 4a). Districts where lions killed domestic livestock were more widespread across the country, with a concentration along the international border adjacent to South Africa's Kruger National Park (Fig. 4b). The number of lions killed in a district (Fig. 4c) was not correlated with the number of people attacked there by lions $\left(r_{\mathrm{s}}=-0.191\right.$, $\mathrm{P}=0.4, \mathrm{n}=19$ districts where lions were killed, people attacked or domestic livestock killed by lions) nor with the number of domestic livestock killed there by lions $\left(r_{\mathrm{s}}=\right.$ $0.018, \mathrm{P}=0.9$ ). The absence of significant correlations may be, at least partly, because of the relatively small number of lions killed (one killed in each of nine districts and $>_{1}$ in three districts).

People were attacked by elephants across Mozambique but most attacks were in the north: $55 \%$ of attacks and $67 \%$ of deaths occurred in 12 districts in northern Mozambique (Fig. 5a). Elephants damaged crops across much of Mozambique (Fig. 5b) but damage was particularly common in the north, in districts south of Lake Cabora Bassa and in southern Mozambique, including districts bordering Gonarezhou National Park in Zimbabwe or Kruger National Park. The number of elephants killed in a district in response to conflicts (Fig. 5c) was more strongly correlated with the number of months when crop raiding by elephants was reported in that district $\left(r_{\mathrm{s}}=0.382, \mathrm{P}=0.004\right.$, $\mathrm{n}=54$ districts where elephants were killed, people attacked or crops raided by elephants) than with the number of people in the district who were attacked by elephants $\left(r_{\mathrm{s}}=0.285\right.$, $\mathrm{P}=0.037$ ).
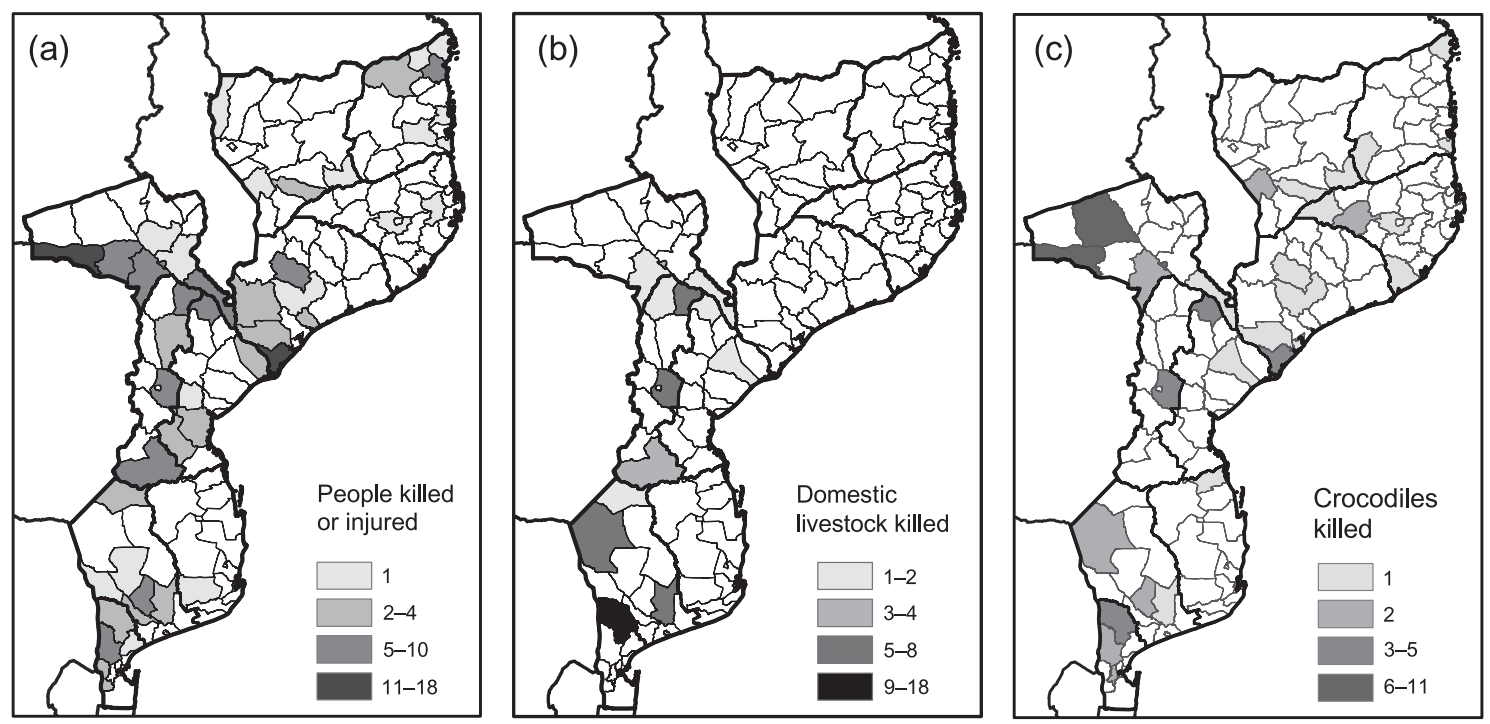

Fig. 2 Human-crocodile conflict reported in the districts of Mozambique during July 2006 to September 2008: (a) people killed or injured by crocodiles, (b) domestic livestock killed by crocodiles, (c) crocodiles killed in response to conflict. Heavy lines indicate provincial boundaries. 

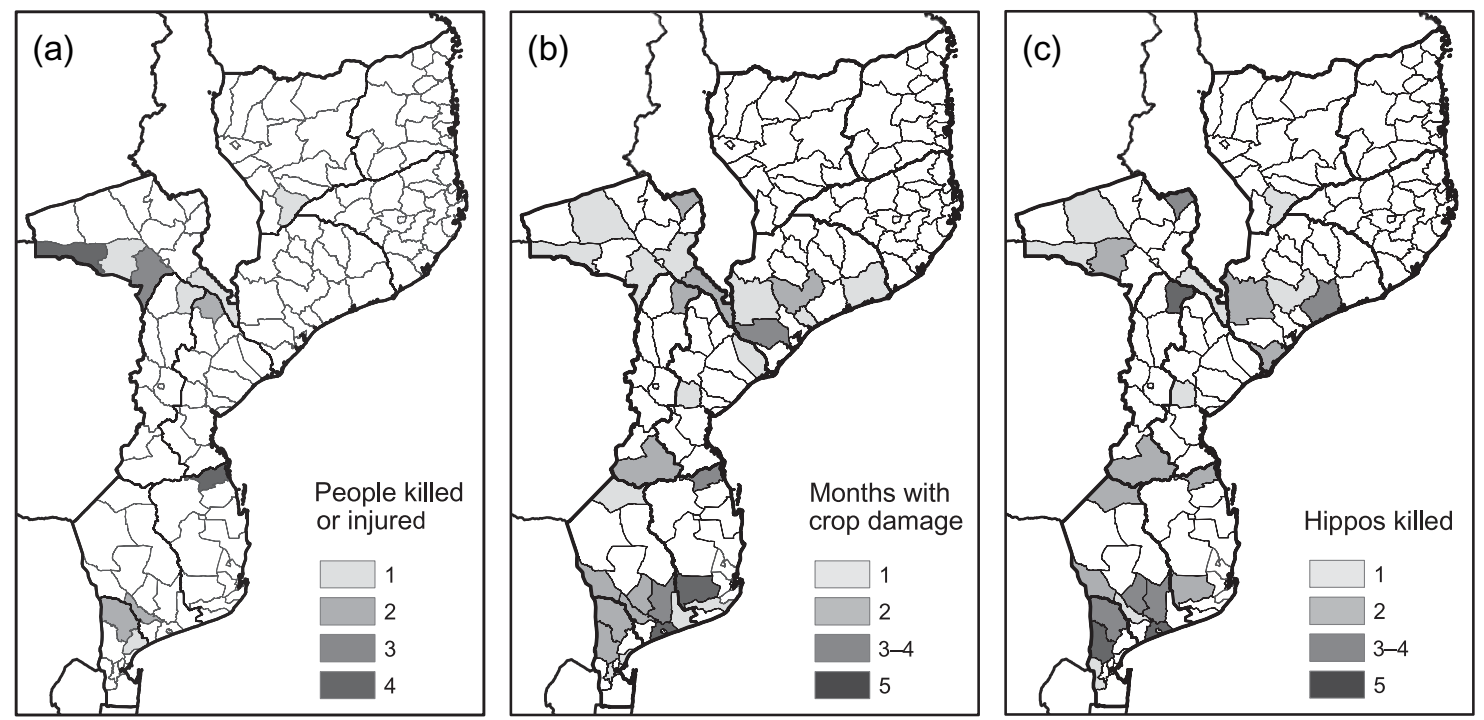

FIG. 3 Human-hippopotamus conflict reported in the districts of Mozambique during July 2006 to September 2008: (a) people killed or injured by hippopotamuses, (b) crop damage by hippopotamuses, (c) hippopotamuses killed in response to conflict. Heavy lines indicate provincial boundaries.

Conflicts with buffaloes were reported mainly from central or southern Mozambique, with a concentration in districts adjacent to Kruger National Park (Fig. 6). Conflicts with hyaena Crocuta crocuta were reported from just three districts that all bordered Kruger or Gonarezhou National Parks.

\section{Discussion}

On average 118 people per year were killed by wildlife in Mozambique and two-thirds of these people were killed by crocodiles. Attacks on humans by crocodiles, although concentrated along the Zambezi River, were more widespread across the country than those by any other species: crocodiles attacked people in $32 \%$ of districts. Crocodiles also attacked domestic livestock. Large mammals are a significant component of the diet of large crocodiles (Corbet, 1960 ) and crocodiles attack people and domestic animals to eat them. The high incidence of crocodile attacks on people probably reflects that crocodiles are widely distributed across the country and that many rural Mozambicans are frequently exposed to attack when they collect water for drinking or washing from rivers or dams, cross rivers or catch fish.

This study revealed a high incidence of lion attacks on people in north-east Mozambique and a high incidence of lions killing domestic livestock near Kruger and Limpopo National Parks. This pattern is confirmed by the recent
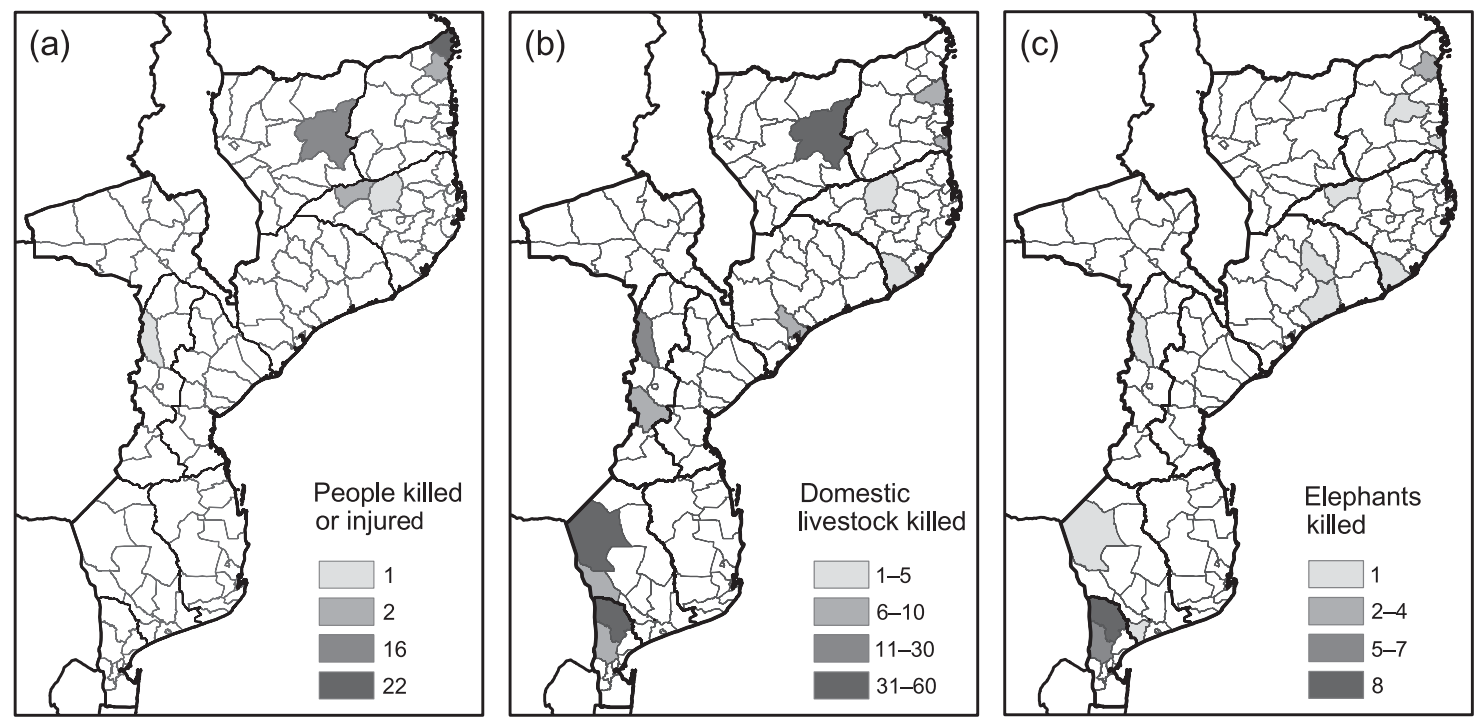

FIG. 4 Human-lion conflict reported in the districts of Mozambique during July 2006 to September 2008: (a) people killed or injured by lions, (b) domestic livestock killed by lions, (c) lions killed in response to conflict. Heavy lines indicate provincial boundaries. 

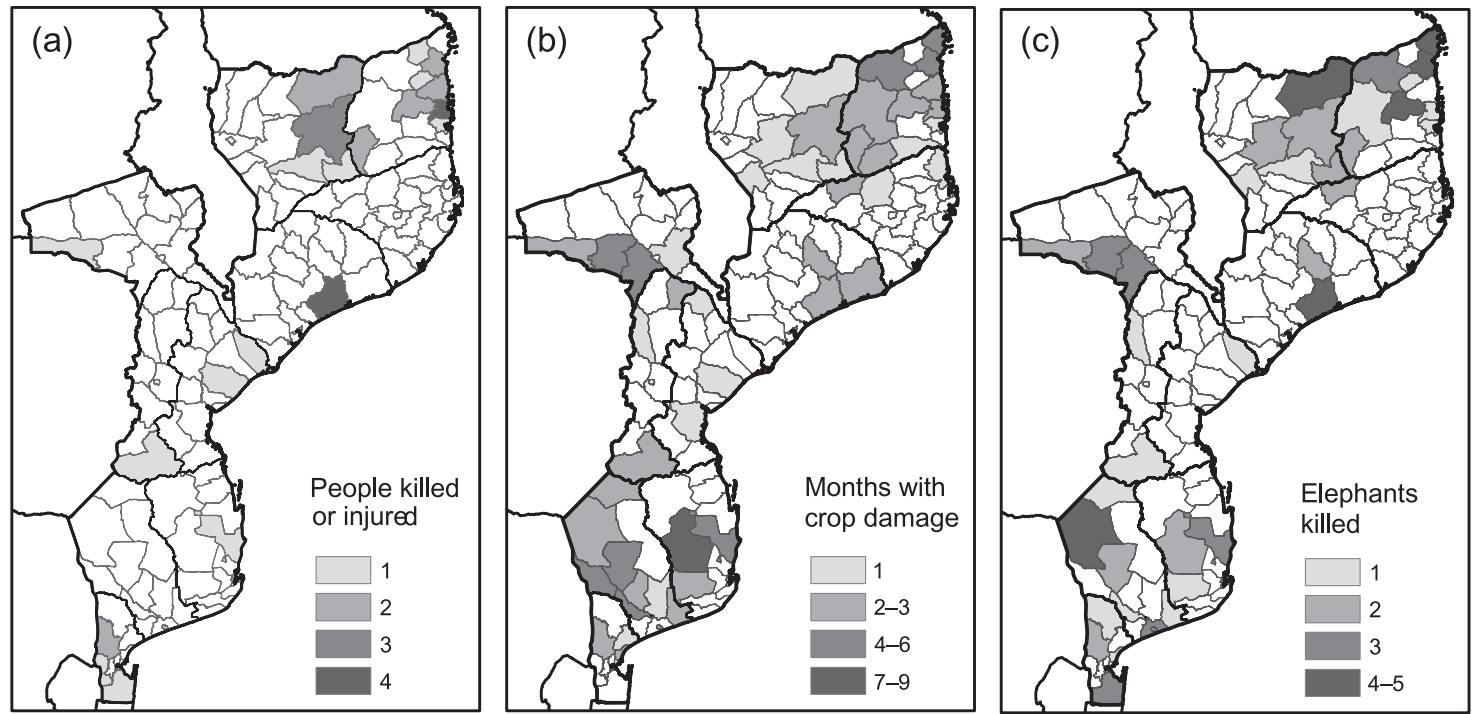

FIG. 5 Human-elephant conflict reported in the districts of Mozambique during July 2006 to September 2008: (a) people killed or injured by elephants, (b) crop damage by elephants, (c) elephants killed in response to conflict. Heavy lines indicate provincial boundaries.

status report for lion in Mozambique (Chardonnet et al., 2009), although the two studies are not totally independent. In our study, two of the six districts where lions attacked people are coastal districts in north-east Mozambique, adjacent to the coastal districts in south-east Tanzania where attacks on people by lions are also common (Packer et al., 2005). Lion attacks on people in Tanzania have increased since 1990, peaking at harvest time each year and being most frequent in areas with few prey apart from bush pig, a common nocturnal crop pest. It is likely that detailed

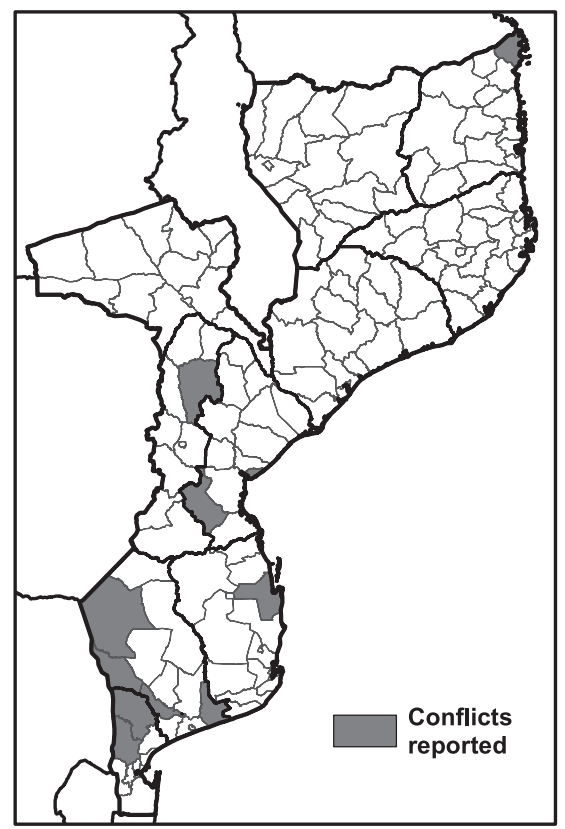

FIG. 6 The districts of Mozambique where human-buffalo conflicts were reported during July 2006 to September 2008. investigation in north-east Mozambique will reveal a similar situation there.

The correlations between the number of conflict species killed in a district and the incidence of differing conflicts suggested that elephants and hippopotamuses were killed primarily because they raided crops. That the numbers of elephants and hippopotamuses killed were large relative to the number of their human victims may be explained by this crop-raiding habit and perhaps by their large body size (which makes them big targets for community hunters and ensures a plentiful supply of meat after they are killed) and, in the case of elephants, by their tusks (which provide a valuable trophy). Although crop raiding may provide local officials with a good reason to kill elephants (notwithstanding that killing some elephants rarely deters others from crop raiding; Hoare, 2001), the opportunity to obtain ivory may be the real reason why many elephants were killed. The difficulty of hunting crocodiles may explain the absence of a correlation between the number of crocodiles killed in each district and the number of people attacked by crocodiles.

Attacks on people by elephants were concentrated largely in northern Mozambique, while crop raiding by elephants was more widespread across the country. But if elephants raid crops in a district it is likely that, sooner or later, people and elephants there will encounter each other in circumstances that lead to a person being attacked by an elephant (e.g. when a subsistence farmer defends his or her crops). Thus, elephant attacks on people may appear to be less widespread across Mozambique than crop raiding simply because of a small data set; elephant attacks on people are rarer than crop raiding and so it may take $>2$ years to provide complete information on the spatial distribution of elephant attacks on people. Similarly, when 
more data are available, it will probably be found that the spatial distribution of hippopotamus attacks on people is more similar to that of crop raiding by hippopotamuses. Also, additional data may show lion attacks on people to be more widespread than our analysis suggests.

At the national level the buffalo appeared to be a minor conflict species, being responsible for the death of one person and injuries to seven. Eleven buffaloes were killed, three of them apparently in response to crop damage. However, the buffalo has the potential to cause conflicts that would not be noted in the DNTF records (Anderson \& Pariela, 2005) because buffalo and domestic cattle share diseases that kill cattle (e.g. corridor disease), affect the economics of cattle rearing (e.g. foot and mouth disease, brucellosis) or can infect people (e.g. bovine tuberculosis, brucellosis).

The spotted hyaena and the leopard were also minor conflict species at the national level. There were no records of leopards attacking people or domestic livestock during 27 months, and hyaenas killed just two cattle and 12 goats. However, hyaenas can cause serious conflict at a local level, having killed four people and injured nine in northern Mozambique during the past 14 years (Begg et al., 2007). During the same period, two people there were injured by leopards.

Specific recommendations to reduce the incidence of attacks by wildlife require more information than is regularly included in the DNTF records, particularly the circumstances of each attack, such as the activity in which the victim was engaged immediately prior to the attack. This study shows where more detailed species-specific studies can most profitably be conducted but most fatal attacks in Mozambique are by crocodiles and suitable mitigation techniques are already known (Fergusson, 2008). Determining why such techniques are not more widely used may be the most appropriate question for future research. The answer is likely to include social, economic and political dimensions. The IUCN SSC African Elephant Specialist Group (undated) concluded that the key to successful mitigation of humanelephant conflict lay in enabling and empowering local people to take greater responsibility for the management of conflict problems and this is probably also true for humancrocodile conflicts. Mitigation techniques such as alternative water supplies and extraction methods, physical barriers and safe transport will not, however, prevent crocodile attacks when people are aware of the danger but take the risk anyway, for example by entering water to fish.

Of 51 people killed by crocodiles in northern Mozambique (Begg et al., 2007), one was collecting water immediately prior to being attacked, 10 were bathing, seven were wading across a river, one fell out of a canoe, seven were fishing with gill nets or rod and line and 25 were in the water fishing with nets or traps. Local people here opportunistically killed crocodiles and destroyed their nests because of the danger they posed and the damage they caused to fishing nets. Nonetheless, the 25 people who were killed while in water, fishing, presumably knew they were risking a crocodile attack (although they may have underestimated the probability of attack) and took the risk because alternative foods or livelihoods were lacking. In other words, these people were killed by crocodiles because they were too poor to feed their family in a manner that did not expose themselves to the risk of being killed by a crocodile. This suggests a link between human-crocodile conflict and poverty, at least in northern Mozambique but probably elsewhere as well.

The removal of crocodiles from waters that no longer contain enough natural food to sustain viable populations of adult crocodiles (Anderson \& Pariela, 2005) and the removal of large crocodiles (Ghiurghi \& Pariela, 2007) have been suggested as means of reducing human-crocodile conflict. Such conflict is so serious in Mozambique that widespread implementation of these policies could have important consequences for crocodile conservation nationally because it has yet to be shown that viable populations of crocodiles exist within Mozambique's protected areas. Several protected areas have major rivers as their boundaries (e.g. the Save River is the northern border of Zinave National Park, the Limpopo and Elefantes Rivers form the eastern and southern borders of Limpopo National Park). Hence, crocodiles living in rivers that form the boundaries of protected areas may cause conflicts even if large crocodiles are removed elsewhere. Furthermore, protected area authorities have no control over fishing in the rivers that form protected area boundaries, or even in rivers inside these areas, because fishing in Mozambique is controlled by fishery legislation, not by conservation laws. While the ecological effects of this situation are significant and negative, any attempt to change it may have major socio-economic consequences because many fishermen depend on fishing for their livelihoods. There may be a similar conservation problem for hippopotamuses, if they were to be removed from rivers outside protected areas to reduce human-hippopotamus conflict, because it has yet to be shown that viable populations of hippopotamuses exist inside Mozambique's protected areas.

It is likely that more detailed study will reveal that elephant and most hippopotamus attacks on people are largely accidental, the unfortunate outcome of close encounters between people and these large herbivores. If land use plans that reduce the incidence of crop raiding by elephants, by increasing the separation between people and elephants (Hoare, 2001), were adopted, these would probably reduce the incidence of people being attacked by elephants.

Problem lions in south-east Tanzania are probably resident animals (Packer et al., 2005) and this is probably also the case in north-east Mozambique. But Anderson \& Pariela (2005) suggested that elsewhere (e.g. in districts bordering Kruger and Limpopo National Parks), problem lions were often animals that had dispersed from conservation areas, 
and they recommended the killing of lions detected outside conservation or hunting areas. No other strategy is likely to prevent human-lion conflict in areas without adequate populations of wild prey (Chardonnet et al., 2008). However, many protected areas in Mozambique (e.g. Quirimbas and Limpopo National Parks, Niassa National Reserve) are occupied by significant numbers of people. The prevention of conflicts with lions and other wildlife in these areas is likely, in the long-term, to depend on people moving out of these areas either by voluntary relocation or by realignment of the conservation area boundaries. This emphasizes the role of land-use planning in reducing human-wildlife conflict.

The districts that border South Africa's Kruger National Park or include Mozambique's Limpopo National Park had a high incidence of conflict: human-buffalo conflicts were concentrated here, as were the only human-hyaena conflicts. Also, while crocodile attacks on people, the killing of domestic livestock by lions, and crop raiding by elephants and hippopotamuses were not restricted to these districts, all were common here. The high incidence of human-wildlife conflicts in these districts has important implications for the development of Great Limpopo Transfrontier Conservation Area, which is intended to encompass Limpopo, Banhine, Zinave, Kruger and Gonarezhou National Parks and the intervening communal lands and to permit wildlife to move with minimal restrictions. But fencing the eastern boundary of Limpopo National Park has already been suggested (Anderson \& Pariela, 2005) as a means of reducing human-wildlife conflict eastwards of the Limpopo River.

There has been extensive research into human-elephant conflicts in Africa (Hoare \& Du Toit, 1999; Hoare, 2000, 2001; O'Connell-Rodwell et al., 2000; De Boer \& Ntumi, 2001; Osborn \& Parker, 2002; Osborn, 2004; Barnes et al., 2005; Chiyo et al., 2005; Sam et al., 2005; Sitati \& Walpole, 2006). Despite this, dealing with problem elephants and their effects on people is one of the most difficult problems facing wildlife managers (Hoare, 2001). The IUCN SSC African Elephant Specialist Group (undated) concluded that, in the long-term, solving human-wildlife conflicts should focus on what the Group described as the root causes of conflict, such as poor land-use planning and the lack of benefits from wildlife for those who bear most of the costs of living with it. Mozambique's national elephant management strategy (DNFFB, 1999) also emphasized the need to develop and implement land-use plans.

\section{Acknowledgements}

This study was conducted in the framework of the National Wildlife Survey Project in Mozambique as a collaboration between AGRECO G.E.I.E. (http://www.agreco.be) and the Ministry of Agriculture of Mozambique. We would like to acknowledge the late Raimundo Cossa, the Director of the
National Directorate for Land and Forests, and his staff for supporting and facilitating the research. Vernon Booth is thanked for valuable discussion about the issues surrounding the boundaries of protected areas in Mozambique. Fay Robertson commented on a draft of this paper.

\section{References}

Anderson, J.L. \& Pariela, F. (2005) Strategies to Mitigate HumanWildlife Conflicts Mozambique. Wildlife Management Working Paper No. 8. FAO, Rome, Italy.

Barnes, R.F.W., Hema, E.M., Nandjui, A., Manford, M., Dubiure, U.F., Danquah, E. \& Boafo, Y. (2005) Risk of crop raiding elephants around the Kakum Conservation Area, Ghana. Pachyderm, 39, 19-25.

Begg, C., Begg, K. \& Muemedi, O. (2007) Preliminary Data on Human-Carnivore Conflict in Niassa National Reserve, Mozambique, Particularly Fatalities due to Lion, Spotted Hyaena and Crocodile. Unpublished Report. Sociedade para a Gestão e Desenvolvimento da Reserva do Niassa, Maputo, Mozambique.

Chardonnet, P., Fritz, H., Crosmary, W., Drouet-Hoguet, N., Mallon, D., BAKKeR, L. et al. (2008) Human-Wildlife Conflict. Lion. The Management of Lion Attacks on Livestock and Humans. Draft for Comment. International Foundation for the Conservation of Wildlife, and Food and Agriculture Organization of the United Nations, Rome, Italy.

Chardonnet, P., Mesochina, P., Renaud, P.-C., Bento, C., Conjo, D., Fusari, A. et al. (2009) Conservation Status of the Lion (Panthera leo Linnaeus 1758) in Mozambique. IGF Foundation, Maputo, Mozambique.

Chiyo, P.I., Cochrane, P.E., Naughton, L. \& Basuta, G.I. (2005) Temporal patterns of crop raiding by elephants: a response to changes in forage quality or crop availability? African Journal of Ecology, 43, 48-55.

Corbet, P.S. (1960) The food of a sample of crocodiles (Crocodylus niloticus L.) from Lake Victoria. Proceedings of the Zoological Society of London, 133, 561-571.

De Boer, W.F. \& Ntumi, C.P. (2001) Elephant crop damage and electric fence construction in the Maputo Elephant Reserve, Mozambique. Pachyderm, 30, 57-64.

DNFFB (Direç̧ão Nacional de Florestas e Fauna Bravia) (1999) National Strategy for the Management of Elephants in Mozambique. Ministerio da Agricultura e Desenvolvimento Rural, Maputo, Mozambique.

Fergusson, R.A. (2008) Techniques for Mitigation of Crocodile Attacks on Rural Communities in Africa. Food and Agriculture Organization of the United Nations, Rome, Italy.

Ghiurghi, A. \& Pariela, F. (2007) Wildife Survey in Machaze. An Assessment of the Medium and Large Wildlife of the Northern Sector of the Machaze District (Manica province, Mozambique) and Recommendations for its Managements. Final Report. Unpublished Report. Direcção Nacional de Terras e Florestas, Departamento de Inventario de Recursos Naturais, Maputo, Mozambique.

Hoare, R.E. (2000) African elephants and humans in conflict: the outlook for coexistence. Oryx, 34, 34-38.

Hoare, R.E. (2001) A Decision Support System for Managing Human-Elephant Conflict Situations in Africa. IUCN/Species Survival Commission African Elephant Specialist Group, Nairobi, Kenya.

Hoare, R.E. \& Du Toit, J.T. (1999) Coexistence between people and elephants in African savannas. Conservation Biology, 13, 633-639. 
INSKip, C. \& Zimmerman, A. (2009) Human-felid conflict: a review of patterns and priorities worldwide. Oryx, 43, 18-34.

IUCN SSC (Species Survival Commission) African Elephant Specialist Group (undated) Evolution of the Human Elephant Conflict Working Group and Synthesis of Key Lessons Learnt. Http:// www.iucn.org/afesg [accessed 26 February 2008].

O'Connell-Rodwell, C.E., Rodwell, T., Rice, M. \& Hart, L.A. (2000) Living with the modern conservation paradigm: can agricultural communities co-exist with elephants? A five-year case study in East Caprivi, Namibia. Biological Conservation, 93, 381-391.

Ogada, M.O., Woodroffe, R., Oguge, N.O. \& Frank, L.G. (2003) Limiting depredation by African carnivores: the role of livestock husbandry. Conservation Biology, 17, 1521-1530.

Osborn, F.V. (1998) Elephant/Human Conflict Around Maputo Elephant Reserve, Mozambique. Unpublished Report. University of Cambridge, Cambridge, UK.

Osвorn, F.V. (2004) Seasonal variation of feeding patterns and food selection by crop-raiding elephants in Zimbabwe. African Journal of Ecology, 42, 322-327.

Osborn, F.V. \& Anstey, S. (2002) Elephant/Human Conflict and Community Development Around the Niassa Reserve, Mozambique. Mid Zambezi Elephant Project, Harare, Zimbabwe.

Osborn, F.V. \& PARker, G.E. (2002) Community-based methods to reduce crop loss to elephants: experiments in the communal lands of Zimbabwe. Pachyderm, 33, 32-38.
Packer, C., Ikanda, D., Kissul, B. \& Kushnir, H. (2005) Lion attacks on humans in Tanzania. Nature, 436, 927-928.

Sam, M.K., Danquah, E., Oppong, S.K. \& Ashie, E.A. (2005) Nature and extent of human-elephant conflict in Bia Conservation Area, Ghana. Pachyderm, 38, 49-58.

Sitati, N.W. \& Walpole, M.J. (2006) Assessing farm-based measures for mitigating human-elephant conflict in Transmara District, Kenya. Oryx, 40, 279-286.

\section{Biographical sketches}

Kevin M. Dunham is a wildlife biologist with interests in the management and conservation of large mammals. ANDREA GHIURGHI is a freelance zoologist and has worked on conservation projects in Africa since 1997. His main interests are wildlife management, protected area management, wildlife monitoring, human-wildlife conflicts, hunting management and ecotourism. ReziA Cumbi is responsible for collating human-wildlife conflict reports at the DNTF in Maputo and working with the provincial authorities to advise on, and provide training in, conflict mitigation. FERDINANDO URBANO specializes in geographical information systems, with a background in environmental engineering. Since 2000 he has worked on remote sensing, spatial databases and data analysis for projects on natural resource management, particularly those focusing on wildlife management, forestry, desertification and water resources. 